\title{
Antibacterial Activity of Endophytic Fungi Isolated from the Bark of Cinnamomum mercadoi
}

\author{
Jia P. Marcellano, Alyssa S. Collanto, Rolly G. Fuentes*
}

Jia P. Marcellano, Alyssa S. Collanto, Rolly G. Fuentes

Division of Natural Sciences and Mathematics, University of the Philippines Visayas Tacloban College, 6500 Tacloban City, PHILIPPINES.

\section{Correspondence}

\section{Rolly G. Fuentes,}

Division of Natural Sciences and Mathematics, University of the Philippines Visayas Tacloban College, 6500 Tacloban City, PHILIPPINES,

Phone no:+63-053-321-8299

E-mail: rgfuentes@up.edu.ph

History

- Submission Date: 22-02-17;

- Review completed: 13-03-17;

- Accepted Date: 24-03-17

DOI : 10.5530/pj.2017.3.69

Article Available online http://www.phcogj.com//v9/i3

\section{Copyright}

(c) 2017 Phcog.Net. This is an openaccess article distributed under the terms of the Creative Commons Attribution 4.0 International license.

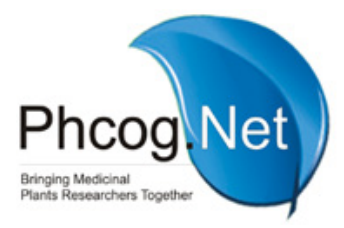

\begin{abstract}
Introduction: Cinnamomum mercadoi is a medicinal tree endemic to the Philippines. Cinnamomum species have been extensively studied for their endophytic fungi with pharmacological importance. This study aims to isolate and evaluate the antibacterial activity of endophytic fungi associated with the bark of $C$. mercadoi. Materials and Methods: Endophytic fungi were isolated from surface sterilized bark samples aseptically. The pure isolates were identified through their morphological characteristics. Agar plug diffusion assay was employed in the primary screening of their antibacterial activity against Staphylococcus aureus, Bacillus cereus, Escherichia coli and Pseudomonas aeruginosa. Four active endophytes were fermented and extracted with ethyl acetate (EtOAc). The antibacterial activity of the EtOAc extracts was screened using the disk diffusion assay. The minimum inhibitory activity (MIC) was evaluated using the microdilution method. Results: Twelve (12) endophytes were isolated from the bark of $C$. mercadoi. All endophytes exhibited antibacterial activity on at least one of the test pathogens. However, only two of the four endophytes subjected to the secondary screening showed wide-spectrum activity and inhibited the growth of all test bacteria. Fusarium sp. 2 was identified to have the most promising activity with MIC values ranging from $2.1-4.2 \mathrm{mg} / \mathrm{mL}$. Conclusion: C. mercadoi harbors endophytes, particularly Fusarium sp. 2, which possess antibacterial activity and thus a potential source of antibacterial compounds. Key words: Fusarium, Cinnamon, Escherichia.
\end{abstract}

\section{INTRODUCTION}

Plants are still considered as one of the important sources of biologically active compounds in natural products research. Many plant species have been utilized globally in traditional healing and have been studied extensively for their pharmacological properties. Medicinal plants are also reported to host some fungi that are involved in the co-production of active metabolites. ${ }^{1}$ These fungi may have also contributed to the biological activities exhibited by the plants. Endophytic fungi are ubiquitous symbiotic to slightly parasitic microorganisms that live within plant tissues for all or part of their life cycle. ${ }^{2}$ Endophytes protect plants against herbivores, insect attacks or tissue invading pathogens and thus show mutualistic, parasitic and commensalistic relationship with its host. ${ }^{3}$ They carry out resistance mechanisms to protect its host plant from pathogenic invasion by producing secondary metabolites having antagonistic activity. With this, endophytic fungi are considered as reservoir of active metabolites that can be used as leads in drug developments. ${ }^{4,5}$

Antimicrobial resistance has been a major health issue and still presents threat to health care system globally. ${ }^{6}$ Studies have shown that microbes have developed resistance to antibiotics through various molecular mechanisms such as prevention of access to drug targets and modification of the drug. ${ }^{7}$ Thus, this global problem has led to the increase in researches featuring endophytic fungi, particularly those isolated from medicinal plants for their potential as source of new antibiotics. ${ }^{8-10}$

Several Cinnamomum species has been studied for their associated endophytes because of their promising antibacterial activity. ${ }^{11-13}$ Moreover, active compounds have been isolated from endophytic fungi associated with this species. Cinnamomum zeylanicum, collected from Honduras, was the host of a novel endophyte Muscador albus which was reported to contain volatile organic compounds with antimicrobial activities. ${ }^{14}$ Antimycobacterial compounds were isolated from Annulohypoxylon ilanense, an endophyte of a Cinnamomum species from Taiwan. ${ }^{15}$ Cinnamomum mercadoi (Lauraceae) is a tree endemic to the Philippines. It is traditionally used as expectorant and for the treatment of digestion problem and tuberculosis. ${ }^{16,17}$ Biological studies of C. mercadoi had shown that its crude extract exhibited analgesic, antimicrobial, antioxidant and antidiarrheal properties. ${ }^{17-19}$ No previous study on its endophytic fungi has been reported to the best of our knowledge. In this study, we have isolated 12 endophytic fungi and screened them for their antibacterial activity. An Ascomycete isolate, Fusarium sp. 2, is being reported to have a broad spectrum and promising antibacterial activity. 


\section{MATERIALS AND METHODS}

\section{Sample Collection}

Bark samples were collected from a healthy Cinnamomum mercadoi tree in Barangay Patag, Baybay, Leyte, Philippines $\left(10.74^{\circ} \mathrm{N}, 124.79^{\circ} \mathrm{E}, 31.5 \mathrm{~m}\right.$ elevation) in December 2015. A $3.0 \times 5.0 \times 1.0 \mathrm{~cm}$ (length $\times$ width $\times$ height) fragment of bark tissue was cut $1.5-2.0 \mathrm{~m}$ above ground level. Samples were placed in ziploc bags, maintained at $4^{\circ} \mathrm{C}$ in an ice box during transport and processed within 48 hours.

\section{Isolation and Culture of Endophytic Fungi}

The bark samples were washed several times under running tap water to remove soil and other debris. The bark sterilization and the culture of endophytic fungi utilized the methods described previously with some modifications. ${ }^{11,20,21}$ The explant was dipped in $70 \%$ ethanol for one minute, $4 \% \mathrm{NaOCl}$ for five minutes, and $96 \%$ ethanol for 30 seconds. The surface sterilized samples were then washed with sterile distilled water thrice and allowed to surface dry under aseptic conditions. After washing, sterile blades were used to excise $0.5 \mathrm{~cm} \times 0.5 \mathrm{~cm}$ pieces of bark. Forty (40) pieces were randomly selected as sources of fungal endophytes. In each Petri dish, four segments were plated on potato dextrose agar (PDA) medium supplemented with streptomycin $(100 \mathrm{mg} / \mathrm{l})$ to inhibit bacterial growth. The Petri dishes were sealed with Parafilm, incubated for 21 days at $27 \pm 3^{\circ} \mathrm{C}$, and examined periodically. Only fungal hyphae emerging from the bark pieces were transferred to PDA plates through hyphal tipping.

The fungi were identified up to the genus level on the basis of their morphological characteristics such as colony topography, color, and growth pattern. Slides were prepared from cultures by hyphal tipping, stained with lactophenol aniline blue and viewed under microscope. The isolates were identified through their reproductive structures. Mycological reference books were used as guides for the morphological identification. ${ }^{22,23}$ The isolates were stored at the Microbiology Laboratory, Division of Natural Sciences and Mathematics, University of the Philippines Visayas Tacloban College.

\section{Test Microorganisms}

Two gram-positive bacteria: Staphylococcus aureus (ATCC 25923) and Bacillus cereus (ATCC 10876) and two gram-negative bacteria: Pseudomonas aeruginosa (ATCC 27853) and Escherichia coli (ATCC 25922) were obtained from the Department of Science and Technology (DOST)Region 8 and were maintained at Nutrient Agar slants and stored at $4{ }^{\circ} \mathrm{C}$.

\section{Agar Plug Diffusion Assay}

The isolated endophytic fungi from C. mercadoi were subjected to preliminary screening through agar plug diffusion method as described with minor modifications. ${ }^{24}$ Endophytic fungi were cultured in PDA for seven days at room temperature. Test bacteria were inoculated in Petri dishes with Mueller-Hinton Agar(MHA).Then, agar plugs with diameter of approximately eight $\mathrm{mm}$ were cut from the PDA plate of actively growing endophytic fungi and were

transferred to the MHA with the test bacteria. These plates were sealed with Parafilm and were kept in a refrigerator at $4^{\circ} \mathrm{C}$ for 12 hours for diffusion of metabolites. The plates were then incubated at room temperature for 12 hours to enable growth of test microorganisms. After incubation, the diameter of the zones of inhibition (ZOI) was measured using a ruler.

\section{Fermentation and Extraction of the Endophytes}

Endophytic fungi which exhibited antibacterial activity in the preliminary screening study were subjected to liquid surface fermentation and ethyl acetate extraction following the methodology described previously. ${ }^{25}$ Three pieces of mycelia agar plugs $\left(0.5 \times 0.5 \mathrm{~cm}^{2}\right)$ were inoculated into $100 \mathrm{~mL}$ Potato Dextrose Broth (PDB). Then, they were incubated at room temperature for three weeks under stationary conditions. After the incubation period, ethyl acetate $(\mathrm{EtOAc})(100 \mathrm{ml})$ was added to the broth culture and the formed mycelial mat was manually macerated using mortar and pestle. Afterwards, the mycelial mat was filtered and the broth was added with EtOAc. After 24 hours, the EtOAc extract was separated from the broth using a separatory funnel and Whatman \# 1 filter paper. The extraction process was repeated three times. The extract was concentrated at in vacuo using a rotary evaporator.

\section{Disk Diffusion Assay}

The EtOAc extracts were tested for their antimicrobial activity using the disk diffusion method prescribed by the NCCLS. ${ }^{26}$ Bacterial suspensions were prepared from $24 \mathrm{~h}$ old culture of the test bacteria. All bacterial suspensions were standardized to contain approximately $1.5 \times 10^{8} \mathrm{CFU} /$ $\mathrm{mL}$ based on $0.5 \mathrm{McF}$ arland Standard. The bacteria were inoculated on dried surface of a Mueller-Hinton Agar (MHA).The inoculum was incubated for 10-15 min to ensure any excess surface moisture to be absorbed and to ensure confluent lawn of bacteria growth before applying the test disks.

The dried crude extracts were dissolved in $0.1 \%$ dimethyl sulfoxide (DMSO) to a concentration of $100 \mathrm{mg} / \mathrm{mL}$. Then, $30 \mu \mathrm{L}$ of the dissolved extract was pipetted to $5-\mathrm{mm}$ diameter sterile circular disks (Whatman Paper No. 1) and was allowed to dry for an hour inside the incubator at $35^{\circ} \mathrm{C}$. In each inoculated MHA plate, five paper disks with the extract were placed equidistantly. Paper disks eluted with $30 \mu \mathrm{L}$ of $0.1 \%$ DMSO and $30 \mu \mathrm{L}$ Streptomycin $(10 \mathrm{mg} / \mathrm{mL})$ were included in the MHA plate as negative and positive controls, respectively. All plates were incubated at room temperature for 24 hours and resulting zones of inhibition were measured.

\section{Minimum Inhibitory Concentration (MIC) Determination}

Minimum inhibitory concentration (MIC) was determined for the crude EtOAc extracts that displayed the highest antibacterial activity. The two-fold broth micro-dilution method recommended by the NCCLS $^{26}$ was used. Crude extracts were tested at concentration ranging from $10 \mathrm{mg} / \mathrm{mL}$ to $78 \mu \mathrm{g} / \mathrm{mL}$. The stock solution of the crude metabolites was prepared by dissolving it with $0.1 \%$ DMSO $(100 \mathrm{mg} / \mathrm{mL})$. Bacterial suspensions were prepared and the turbidity was adjusted to $10^{5} \mathrm{CFU} / \mathrm{mL}$ using the $0.5 \mathrm{McF}$ arland standard. The medium and extract dilution were inoculated with $50 \mu \mathrm{L}$ bacterial suspension and was incubated at $35^{\circ} \mathrm{C}$ for 18 to 20 hours. The lowest concentration of the extract which inhibited the visible growth of the microorganism was recorded.

\section{Data Analyses}

All tests were carried out in three replications. The values obtained are presented as mean \pm standard deviation $(n=3)$.

\section{RESULTS}

Twelve (12) fungal isolates belonging to 9 genera of filamentous fungi were obtained from the inner bark of C. mercadoi. The composition of fungi included the Ascomycetes Colletotrichum and Fusarium; the Zygomycetes Cunninghamella and Mucor; the Deuteromycetes Aspergillus, Penicillium, Pestalotiopsis, Phomopsis, and Rhizoctonia. Reproductive structures were not observed in one strain and the endophyte was assigned as Mycelia sterilia.

All isolated endophytes inhibited at least one pathogenic bacterium in the agar plug diffusion assay and created zones of inhibition ranging from 8.3 to $19.7 \mathrm{~mm}$ (Table 1). Among the four test bacteria, S. aureus was inhibited by most endophytes while $E$. coli was the least inhibited. Highest antibacterial activity was shown by Cunninghamella sp. which inhibited all test bacteria. Isolates from the genera Rhizoctonia, Fusarium 
Table 1: Antibacterial activity of the endophytic fungi isolated from the bark of Cinnamomum meradoi

\begin{tabular}{|c|c|c|c|c|c|}
\hline \multirow{3}{*}{ Isolate Code } & & \multicolumn{4}{|c|}{ Zone of Inhibition $(\mathrm{mm})^{* a}$} \\
\hline & & \multicolumn{2}{|c|}{ Gram positive bacteria } & \multicolumn{2}{|c|}{ Gram negative bacteria } \\
\hline & & S. aureus & B. cereus & E. coli & E. aerogenes \\
\hline & Streptomycin & $29.7 \pm 4.5$ & $21.0 \pm 4.0$ & $15.7 \pm 4.5$ & $26.3 \pm 3.2$ \\
\hline & Distilled water & $-{ }^{\dagger}$ & - & - & - \\
\hline 1.1 & Cunninghamella sp. & $10.4 \pm 0.6$ & $9.7 \pm 0.6$ & $9.7 \pm 0.6$ & $17.0 \pm 1.0$ \\
\hline 10.1 & Rhizoctonia sp. 1 & - & - & - & $8.7 \pm 0.3$ \\
\hline 10.2 & Rhizoctonia sp. 2 & $13.3 \pm 0.6$ & $17.7 \pm 1.5$ & - & $14.0 \pm 5.6$ \\
\hline 4.1 & Colletotrichum sp. & $10.7 \pm 4.6$ & - & - & - \\
\hline 4.3 & Mucor sp. & $9.3 \pm 0.6$ & - & - & - \\
\hline 4.4 & Phomopsis sp. & $11.0 \pm 0.0$ & - & - & - \\
\hline 5.5 & Aspergillus sp. & - & $8.3 \pm 0.6$ & - & - \\
\hline 7.1 & Penicillium sp. & $14.0 \pm 4.6$ & - & - & $13.7 \pm 5.1$ \\
\hline 10.3 & Pestalotiopsis sp. & - & - & $11.0 \pm 0.0$ & - \\
\hline 9.3 & Fusarium sp. 1 & $14.0 \pm 5.3$ & $16.7 \pm 7.6$ & - & $16.3 \pm 6.4$ \\
\hline 10.4 & Fusarium sp. 2 & $9.0 \pm 1.7$ & $13.3 \pm 2.1$ & - & $12.7 \pm 3.5$ \\
\hline 3.1 & Mycelia sterilia & $12.7 \pm 6.4$ & $19.7 \pm 5.9$ & - & $16.3 \pm 2.5$ \\
\hline
\end{tabular}

${ }^{*}$ :mean diameter of zone of inhibition \pm S.D. $(\mathrm{n}=3)$

a: agar plug diameter is $8 \mathrm{~mm}$

$\dagger:(-)$ no zone of inhibition observed

Table 2: Minimum inhibitory concentration of the ethyl acetate extract of Fusarium sp. 2 isolated from the bark of Cinnamomum mercadoi

\begin{tabular}{cc}
\hline Test bacteria & $\mathrm{MIC}(\mathrm{mg} / \mathrm{mL})^{*}$ \\
\hline E. coli & $2.1 \pm 0.7$ \\
E. aerogenes & $4.2 \pm 1.4$ \\
S. aureus & $4.2 \pm 1.4$ \\
B. cereus & $3.8 \pm 2.2$ \\
\hline
\end{tabular}

${ }^{*}$ Data are presented as mean + S.D. $(n=3)$.

and Mycelia sterilia showed broad spectrum activity as they inhibit the growth of both gram positive and gram negative bacteria.

The five endophytes which showed relatively the highest antibacterial activity, Cunninghamella, Rhizoctonia sp. 2, Fusarium sp. 1, Fusarium sp. 2 and Mycelia sterilia were further evaluated for their antibacterial activity using the liquid fermentation assay. At a concentration of $10 \mathrm{mg} / \mathrm{mL}$, the EtOAc extracts of Cunninghamella sp. and Fusarium sp. 2 showed inhibitory activity against the four tested bacteria (Figure 1). On the other hand, Fusarium sp. 1, Rhizoctonia sp. and Mycelia sterilia showed only moderate antibacterial activity against the gram-positive bacteria.

The MIC of Fusarium sp. 2 EtOAc extract was determined through broth microdilution method because of its promising activity in the secondary screening i.e. high inhibitory zone observed and wider activity spectrum. Results showed that the lowest minimum inhibitory concentration was observed in E. coli among the four bacteria tested (Table 2).

\section{DISCUSSION}

Cinnamomum species had been studied extensively for the biological activities of the endophytic fungi associated with the plant. Antimicrobial activity was exhibited by some endophytic fungal isolates from C. burmani, C. camphora, and C. insularimontanum and C. zeylanicum. ${ }^{11-14}$ In the

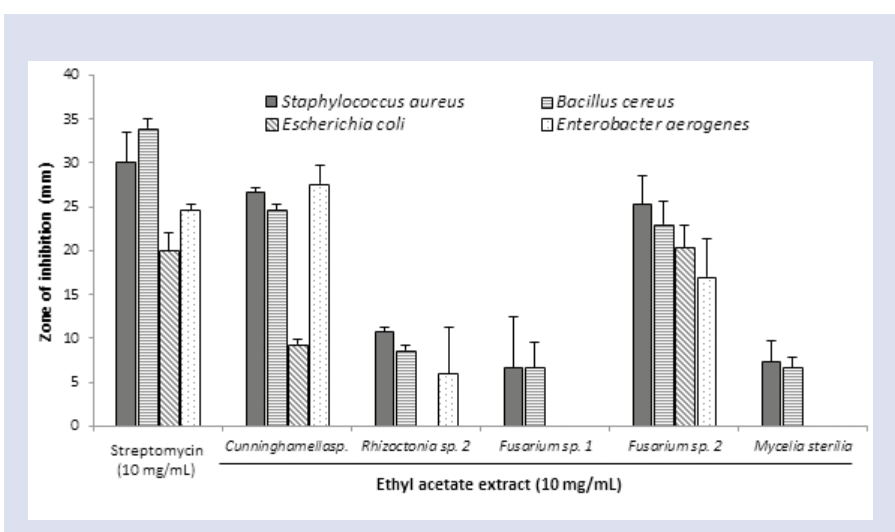

Figure 1: Antibacterial activity of the ethyl acetate extracts of Cunningamella sp., Rhizoctonia sp., Fusarium sp. 1, Fusarium sp. 2 and Mycelia sterilia using the Kirby-Bauer disk diffusion assay. The size of the disks is $5 \mathrm{~mm}$. Data are shown as mean \pm S.D. $(n=3)$.

present work, 12 endophytic fungi from the inner bark of C. mercadoi, an endemic plant of the Philippines, were isolated and investigated for their antibacterial activity. All endophytes showed growth inhibitory activity against at least one of the test pathogens. Most of the isolated fungi had antibacterial activity only against the gram positive bacteria. The activity exhibited by the endophytes from C. mercadoi can be said to be in agreement with the antibacterial activity reported in previous studies using its bark extract. ${ }^{17,18}$ The bark extract of $C$. mercado $i$ was only active against the gram-positive bacteria Staphylococcus aureus and Bacillus subtilis. In general, crude extracts often show better activity against gram positive bacteria because of their structural differences. ${ }^{27}$ In this study, however, the endophytes Cunninghamella sp., Fusarium sp. 1, Fusarium sp. 2, Rhizoctonia sp. and Mycelia sterilia had shown antibacterial activity against gram negative bacteria during the primary screening. However, 
only Cunninghamella sp. and Fusarium sp. 2 had retained their effectiveness against the four tested bacteria in the fermentation assay. This observation was also reported in several studies in which endophytic fungi showed activity in the solid media but not when subjected to fermentation. This was attributed to the possible contribution of the type of media and culture condition in the biosynthesis of the active metabolites. ${ }^{9,28}$ Since host plant affects metabolite production of endophytic fungi, further study on whether biosynthesis of active metabolites continues or stops once the fungi are grown in vitro is also needed. ${ }^{5}$ But, Fusarium sp. 2 showed more effectivity as it also inhibited the growth of the gram negative $E$. coli when it was cultured in the liquid medium. No activity against E. coli was observed during the primary screening. Though the MIC of Fusarium sp 2 against the four tested bacteria suggests moderate activity, the endophyte can still be considered a potential source of antibacterial. Studies had reported the antibacterial activity of endophytic fungi belonging to Fusarium genera isolated from other medicinal plants such as Ophiopogon japonicus, ${ }^{10}$ Aqularia sinensis ${ }^{29}$ and Taxus baccata. ${ }^{30}$ The genera Fusarium has been reported to be a rich source of diverse compounds with antibacterial activities. Beauvericin, isolated from F. oxysporum, which is associated with Cinnamomum kanihirai, was reported toxic against methicillin-resistant $S$. aureus and B. subtilis. ${ }^{31}$ The endophyte of Magnolia x soulangeana, F. dimerum, was the source of enniatins which exhibited effectiveness against Bacillus subtilis, Candida albicans, Trychosporom cutaneum and Cryptococcus neoformans. ${ }^{32}$ Moderate inhibitory activity against Staphylococcus aureus and Pseudomonas aeruginosa was exhibited by the fusaequisin A, a polyketide isolated isolated from Fusarium equiseti which is an endophytic fungi of Ageratum conyzoides. ${ }^{33}$ In C. mercadoi, the antibacterial activity exhibited by Fusarium sp. suggests that it can be also potential source of antibacterial compounds. One major advantage of the utilization of endophytic fungi in drug discovery is that their diversity offers an abundant source of novel and active metabolites. Moreover, endophytes can be the alternative source of compounds isolated from plants thus eliminating the utilization of large quantity of plant material in producing the compound. ${ }^{1}$ Taxol, an anticancer natural product which was obtained originally from a yew plant, can also be obtained from endophytes. ${ }^{34}$

\section{CONCLUSION}

Our preliminary study had demonstrated that C. mercadoi is a host to endophytic fungi which are potential source of antibacterial compounds. Among the endophytes, Fusarium sp. 2 showed the most promising antibacterial activity. It can be also inferred that the endophytes present in the bark may have contributed to the antibacterial activity of $C$. mercadoi. Further studies on the molecular identification of Fusarium sp. 2 and on isolation of the bioactive compounds responsible for its activity are now needed.

\section{ACKNOWLEDGEMENT}

We are grateful to Dr. Naomi Tangonan and Mr. Salvador Inocencio for the assistance in the identification of the endophytic fungi, and to Mr. Antonio Fernandez for helping us in the collection of the bark samples.

\section{CONFLICT OF INTEREST}

None

\section{ABBREVIATIONS USED}

MIC: Minimum inhibitory concentration; PDA: potato dextrose agar; PDB: potato dextrose broth; MHA: Mueller-Hinton Agar; CFU: colony forming unit; EtOAc: ethyl acetate; DMSO: dimethyl sulfoxide.

\section{REFERENCES}

1. Alvin A, Miller $\mathrm{KI}$, Neilan BA. Exploring the potential of endophytes from medicinal plants as sources of antimycobacterial compounds. Microbiol Res. 2014;169(7):483-95. https://doi.org/10.1016/j.micres.2013.12.009; PMid:24582778.

2. Strobel G, Daisy B. Bioprospecting for microbial endophytes and their natural products. Microbiology Mol Biol Rev. 2003;67(4):491-502.https://doi.org/10.1128/ MMBR.67.4.491-502.2003; PMCid:PMC309047.

3. Singh LP, Gill SS, Tuteja N. Unraveling the role of fungal symbionts in plant abiotic stress tolerance. Plant Signal Behav. 2011;6:175-91. https://doi. org/10.4161/psb.6.2.14146; PMid:21512319 PMCid:PMC3121976.

4. Strobel GA. Endophytes as sources of bioactive products. Microbes Infect. 2003;5(6):535-44. https://doi.org/10.1016/S1286-4579(03)00073-X.

5. Owen NL, Hundley N. Endophytes--the chemical synthesizers inside plants. Sci Prog. 2004;87(2):79-99. https://doi.org/10.3184/003685004783238553.

6. Ferri M, Ranucci E, Romagnoli P, Giaccone V. Antimicrobial Resistance: A global emerging threat to public health systems. Crit Rev Food Sci Nutr. 2015. https:// doi.org/10.1080/10408398.2015.1077192; PMid:26464037

7. Blair JMA, Webber MA, Baylay AJ, Ogbolu DO, Piddock LJV. Molecular mechanisms of antibiotic resistance. Nat Rev Microbiol. 2015;13:42-51. https://doi. org/10.1038/nrmicro3380.

8. Radu S, Kqueen CY. Preliminary screening of endophytic fungi from medicinal plants in Malaysia for antimicrobial and antitumor activity. Malaysian J Med Sci. 2002;9:23-33. PMid:22844221 PMCid:PMC3406204.

9. De Siqueira VM, Conti R, De Araújo JM, Souza-Motta CM. Endophytic fungi from the medicinal plant Lippia sidoides Cham. and their antimicrobial activity 2011;53(2):89-95

10. Liang H, Xing Y, Chen J, Zhang D, Guo S, Wang C. Antimicrobial activities of endophytic fungi isolated from Ophiopogon japonicus (Liliaceae). BMC Complement Altern Med. 2012;12(1):238. https://doi.org/10.1186/1472-6882-12-238; PMid:23190550 PMCid:PMC3534486

11. Kharwar RN, Maurya AL, Verma VC, Kumar A, Gond SK, Mishra A. Diversity and antimicrobial activity of endophytic fungal community isolated from medicinal plant Cinnamomum camphora. Proc Natl Acad Sci India Sect B Biol Sci. 2012;82(4)s:557-65.

12. Praptiwi, Ilyas M, Fathoni A, Wulansari D, Agusta A. Antibacterial screening of the culture of endophytic fungal extracts isolated from cinnamon stick. Tekno Indones. 2015;38(1):33-41.

13. Ho MY, Chung WC, Huang HC, Chung WH, Chung WH. Identification of endophytic fungi of medicinal herbs of Lauraceae and Rutaceae with antimicrobial property. Taiwania. 2012;57(3):229-41.

14. Strobel GA, Dirkse E, Sears J, Markworth C. Volatile antimicrobials from Muscodor albus, a novel endophytic fungus. Microbiology. 2001;147(11):2943-50. https://doi.org/10.1099/00221287-147-11-2943; PMid:11700345

15. Wu M-D, Cheng M-J, Chen I-S, Su Y-S, Hsieh S-Y, Chang H-S et al. Phytochemical investigation of Annulohypoxylon ilanense, an endophytic fungus derived from Cinnamomum species. Chem Biodivers. 2013;10(3):493-505. https://doi. org/10.1002/cbdv.201200418.

16. Lanting Jr MV, Palaypayon CM. Forest Tree Species with Medicinal Uses. Ecosystems Research and Development Bureau, Department of Environment and Natural Resources,Los Banos, Laguna, Philippines; 2002. Available at: http:// erdb.denr.gov.ph/files/publications/denr/denr_v11.pdf.

17. Torres RC, Sison FM, Ysrael MC. Phytochemical screening and biological studies on the crude methanol extract of Cinnamomum mercadoi, Vidal. Philipp J Sci. 2003;132(1):27-32.

18. Fuentes RG, Diloy FN, Tan IL, Balanquit BJR. Antioxidant and antibacterial properties of crude methanolic extracts of Cinnamomum mercadoi Vidal. Philipp J Nat Sci. 2010;15:9-15

19. Gorgonio SRP, Fuentes RG. Antidiarrheal activity of Cinnamomum mercadoi methanolic leaf and bark extracts. Philipp J Nat Sci. 2011;1:43-7.

20. Strobel G, Yang X, Sears J, Kramer R, Sidhu RS, Hess WM. Taxol from Pestalotiopsis microspora, an endophytic fungus of Taxus wallachiana. Microbiology. 1996;142(2):435-40. https://doi.org/10.1099/13500872-142-2-435; PMid:8932715

21. Saithong $P$, Panthavee $W$, Stonsaovapak S, Congfa L. Isolation and primary identification of endophytic fungi from Cephalotaxus mannii trees. Maejo Int J Sci Technol. 2010;4(3):446-53

22. Barnett HL, Hunter BB. Illustrated Genera of Imperfect Fungi. 3rd ed. Minneapolis, Minnesota: Burgess Pub Co; 1972

23. Webster J, Weber RWS. Introduction to Fungi. 3rd ed. New York, USA Cambridge University Press; 2007. https://doi.org/10.1017/CBO9780511809026.

24. Zhang $Y, M u ~ J$, Feng $Y$, et al. Broad-spectrum antimicrobial epiphytic and endophytic fungi from marine organisms: isolation, bioassay and taxonomy. Mar Drugs. 2009;7(2):97-112. https://doi.org/10.3390/md7020097; PMid:19597575 PMCid:PMC2707037

25. Radji M, Sumiati A, Rachmayani R, Elya B. Isolation of fungal endophytes from Garcinia mangostana and their antibacterial activity. African J Biotechnol. 2011;10(1):103-7.

26. National Committee for Clinical Laboratory Standards (NCCLS). Performance 
Standards for Antimicrobial Disk and Dilution Susceptibility Testing; Fourteenth Informational Supplement NCCLS documents M100-S14. 2004. Wayne, Pennsylvania, USA.

27. Denyer SP, Maillard J-Y. Cellular impermeability and uptake of biocides and antibiotics in gram-positive bacteria and mycobacteria. J Appl Microbiol. 2002;92:46S-54S. https://doi.org/10.1046/j.1365-2672.92.5s1.19.x; https://doi. org/10.1046/j.1365-2672.92.5s1.7.x

28. dos Santos IP, da Silva LC, da Silva MV, de Araújo JM, Cavalcanti Mda S, Lima VL. Antibacterial activity of endophytic fungi from leaves of Indigofera suffruticosa Miller (Fabaceae). Front Microbiol. 2015;6. https://doi.org/10.3389/ fmicb.2015.00350.

29. Cui J, Guo S, Xiao P. Antitumor and antimicrobial activities of endophytic fungi from medicinal parts of Aquilaria sinensis. J Zhejiang Univ-Sci B (Biomed Biotechnol). 2011;12(5):385-92. https://doi.org/10.1631/jzus.B1000330; PMid:21528493 PMCid:PMC3087095.

30. Tayung K, Barik BP, Jagadev PN, Mohapatra UB. Phylogenetic investigation of endophytic Fusarium strain producing antimicrobial metabolite isolated from Himalayan Yew Bark. Malays J Microbiol. 2011;7(1):1-6. https://doi.org/10.21161/ mjm.23810.

31. Wang Q-X, Li S-F, Zhao F, Dai H-Q, Bao L, Ding R et al. Chemical constituents from endophytic fungus Fusarium oxysporum. Fitoterapia. 2011:82(5):777-81. https://doi.org/10.1016/j.fitote.2011.04.002; PMid:21497643.

32. Firakova S, Sturdikoca M, Liptaj T, Bezakova L, Proksa B. Enniatins produced by Fusarium dimerum, an endophytic fungal strain. Pharmazie. 2008;63(7):539-41. PMid:18717491.

33. Shiono $Y$, Shibuya $F$ Murayama $T$, Koseki $T$, Poumale HMP Ngadjui BT. A polyketide metabolite from an endophytic Fusarium equiseti in a medicinal plant. Zeitschrift fur Naturforsch - Sect C J Biosci. 2013;68(3):289-92. https://doi. org/10.5560/znb.2013-3014

34. Strobel GA, Hess WM, Ford E, Sidhu RS, Yang X. Taxol from fungal endophytes and the issue of biodiversity. J Ind Microbiol. 1996;17(5):417-23. https://doi. org/10.1007/BF01574772.

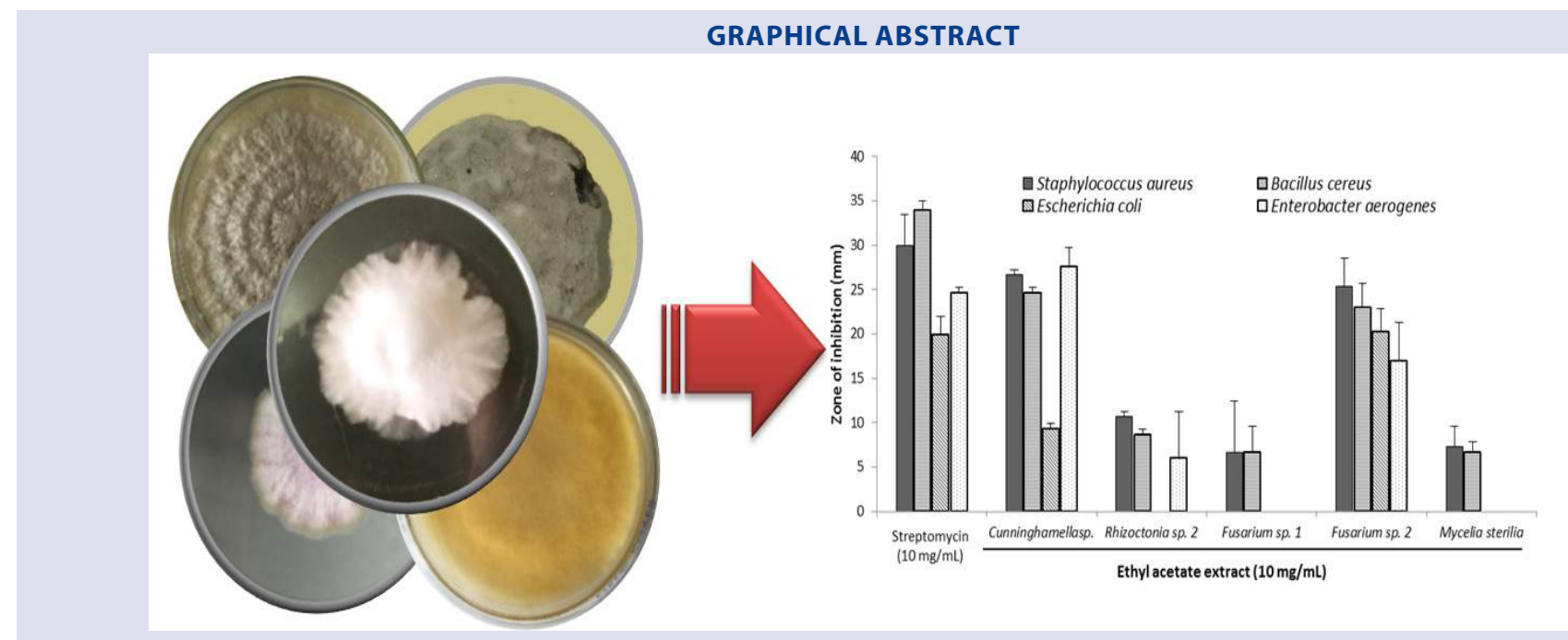

\section{SUMMARY}

- Twelve endophytes were isolated and identified from the bark of Cinnamomum mercadoi.

- The ethyl acetate extract of Fusarium sp. 2 exhibited growth inhibitory activity against the gram positive (Staphylococcus aureus and Bacillus cereus) and gram negative (Escherichia coli and Pseudomonas aeruginosa) bacteria.

\section{ABOUT AUTHORS}

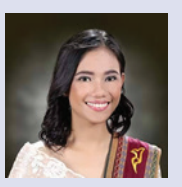

Jia P. Marcellano is an instructor in biology at the Division of Natural Sciences and Mathematics, University of the Philippines Visayas Tacloban College (Philippines). She obtained her BS Biology from the same university.

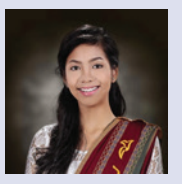

Alyssa S. Collanto obtained her BS Biology at the Division of Natural Sciences and Mathematics, University of the Philippines Visayas Tacloban College (Philippines).

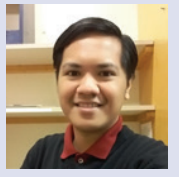

Rolly G. Fuentes, PhD is an Associate Professor in Chemistry at the Division of Natural Sciences and Mathematics, University of the Philippines Visayas Tacloban College (Philippines).

Cite this article: Marcellano JP, Collanto AS, Fuentes RG. Antibacterial Activity of Endophytic Fungi Isolated from the Bark of Cinnamomum mercadoi. Pharmacogn J. 2017:9(3):405-9. 